moderate to severe COPD. Respir Med 2005:99:444-50.

16 Lundback B, Lindberg A, Lindstrom $M$, et al. No 15 but $50 \%$ of smokers develop COPD? Report from the Obstructive Lung Disease in Northern Sweden studies. Respir Med 2003:97:1 15-22.

17 US Department of Health and Human Services, Public Health Service, Centers for Disease Control, et al. Women and smoking: a report of the Surgeon General. Atlanta, GA: Department of Health and Human Services, 2001.

18 US Department of Health and Human Services, Public Health Service, Centers for Disease
Control, et al. The health consequences of smoking: a report of the Surgeon General. Atlanta, GA: Department of Health and Human Services, 2004.

19 US Department of Health and Human Services, Public Health Service, Centers for Disease Control, et al. Reducing tobacco use: a report of the Surgeon General. Atlanta, GA: Department of Health and Human Services, 2000.

20 Anthonisen NR, Connett JE, Kiley JP, et al. Effects of smoking intervention and the use of an inhaled anticholinergic bronchodilator on the rate of decline of $\mathrm{FEV}_{1}$ : the Lung Health Study. JAMA 1994;272:1497-505.
21 Willemse BW, PostmaDS, Timens W, etal. The impact of smoking cessation on respiratory symptoms, lung function, airway hyperresponsiveness and inflammation. Eur Respir J 2004;23:464-76.

22 Hnizdo E, Sullivan PA, Bang KM, et al. Association between chronic obstructive pulmonary disease and employment by industry and occupation in the US population: a study of data from the Third National Health and Nutrition Examination Survey. Am J Epidemiol 2002; 156:738-46

23 Trupin L, Earnest G, San Pedro M, et al. The occupational burden of chronic obstructive pulmonary disease. Eur Respir J 2003;22:462-9.

\title{
Alpha-1-antitrypsin augmentation treatment: does one size fit all?
}

\section{J Stolk}

\section{A new model for the individual pharmacokinetic assessment of patients requiring AAT augmentation therapy}

A lpha-1-antitrypsin (AAT) is synthesised and secreted in the liver by hepatocytes. Individuals who inherit homozygous $\mathrm{Z}$ alleles of AAT have a serum deficiency (AATD) resulting from accumulation of aberrant polymerised AAT in the endoplasmic reticulum of hepatocytes. ${ }^{1}$ The most specific therapeutic approach for AATD is augmentation therapy-that is, intravenous administration of purified AAT which aims to raise serum levels above the protective threshold of $0.5 \mathrm{~g} / \mathrm{l}$ $(\sim 11 \mu \mathrm{M})$ to protect against proteolytic destruction of alveoli and development of emphysema. ${ }^{2}$ Based on current understanding, and confirmed by the American Food and Drug Administration CBER Blood Products Advisory Committee in 1998, the risk of emphysema increases as the serum level of AAT falls below a socalled "protective" threshold of $11 \mu \mathrm{M}$. Of the approximately 100 different alleles for AAT variants, 10-15 are associated with serum levels below this threshold while the $\mathrm{Z}$ allele is by far the most common deficient variant, accounting for 95\% of the clinically recognised cases of severe AATD. ${ }^{4}$

The first study that applied infusions of pooled human plasma purified AAT at doses of $60 \mathrm{mg} / \mathrm{kg}$ once weekly showed that the serum levels could be restored to even above the protective level. ${ }^{5}$ Subsequent studies examined other doses and administration intervals and used different outcome measures and study designs. ${ }^{6}$ In those studies a high level of variability between subjects was seen in the trough serum level in response to dosing.
AAT augmentation treatment is now available in more than 10 countries around the world and the product is provided by an increasing number of pharmaceutical companies. Remarkably, the cost of this expensive treatment did not decline when more suppliers came on the market. This warrants an optimal dosing regimen for individual patients, an aspect that is addressed by Soy et al in this issue of Thorax. ${ }^{7}$ By applying population pharmacokinetic simulation, the authors showed that intervals between infusions of more than 1 week are possible in most patients while maintaining an appropriate threshold level of serum AAT. Soy and co-workers provide a model (in Appendix 2 of their paper) that can be easily used by physicians for tailoring a treatment regimen satisfying both the patient's desired frequency of infusions and the optimal trough level of AAT. Schedules with an interval longer than 1 week are more convenient for patients who can only receive their treatment in clinics rather than at home.

Piitulainen et al have previously shown that reduction of infusion frequency to every 3 days saves on the cost of the product while maintaining a more stable AAT plasma level. ${ }^{8}$ Their approach was proposed for self-treatment at home. Taken together, the data of Soy and Piitulainen suggest that every newly detected patient who fits the criteria for AAT augmentation treatment should have an individual pharmacokinetic assessment after the first infusion(s).

So far, only the biochemical efficacy of the augmentation treatment has been shown, while the effect on biomarkers relevant to the development of emphysema or clinical efficacy of AAT on pulmonary function and emphysema progression by controlled clinical trials is still unknown. To conduct studies that address these issues is difficult because of the rare occurrence of AATD and its inherent wide geographical spread of patients within a country. However, the model presented by Soy et al facilitates the design of such studies because the dosing regimen can now easily be tailored to a predefined trough level of AAT to investigate its effect on selected biomarkers. This may answer the question as to whether the $11 \mu \mathrm{M}$ trough level is a size that should fit all patients or whether more tailored dosing is a prerequisite for the detection of clinical benefit of this treatment.

Thorax 2006;61:1034.

doi: 10.1136/thx.2006.067710

Correspondence to: Dr J Stolk, Department of Pulmonology, Leiden University Medical Center, P O Box 9600, 2300 RC Leiden, The Netherlands; j.stolk.long@lumc.nl

Competing interests: none declared.

\section{REFERENCES}

1 Carrell RW, Lomas DA. Alpha-1-antitrypsin deficiency: a model for conformational diseases. N Engl J Med 2002;346:45-53.

2 American Thoracic Society/European Respiratory Society. Statement: standards for the diagnosis and management of individuals with alpha-1-antitrypsin deficiency. Am J Respir Crit Care Med 2003;168:818-900.

3 Gadek JE, Crystal RG. Experience with replacement therapy in the destructive lung disease associated with severe alpha-1-antitrypsin deficiency. Am Rev Respir Dis 1983;127:S45-6.

4 Demeo DL, Silvermann EK. Alpha-1-antitrypsin deficiency-2: Genetic aspects of alpha(1)antitrypsin deficiency: phenotypes and genetic modifiers of emphysema risk. Thorax 2004;59:259-64.

5 Wewers MD, Casolaro MA, Sellers SE, et al Replacement therapy for alpha 1-antitrypsin deficiency associated with emphysema. N Engl J Med 1987;316:1055-62.

6 Stoller JK, Aboussouan LS. Alpha-1-antitrypsin deficiency-5: Intravenous augmentation therapy: current understanding. Thorax 2004:59:708-12.

7 Soy D, de la Roza C, Lara B, et al. Alpha-1antitrypsin deficiency: optimal therapeutic regimen based on population pharmacokinetics. Thorax 2006:61:1059-64.

8 Piitulainen E, Bernspång $E$, Björkman S, et al. Tailored pharmacokinetic dosing allows selfadministration and reduces the cost of IV augmentation therapy with human $\alpha_{1}$-antitrypsin. Eur J Clin Pharmacol 2003;59:151-6. 